Working Paper 2009:1

Department of Economics

Vacancy Referrals, Job Search, and the Duration of Unemployment: A Randomized Experiment

Per Engström, Patrik Hesselius and Bertil Holmlund 
Department of Economics

Uppsala University

P.O. Box 513

SE-751 20 Uppsala

Sweden

Fax: $+{ }_{4} 6184711478$
Working paper 2009:1

February 2009

ISSN $1653-6975$

Vacancy Referrals, Job Search, and the Duration of Unemployment:

A RANDOMIZED EXPERIMENT

Per Engström, Patrik Hesselius and Bertil Holmlund

Papers in the Working Paper Series are published on internet in PDF formats.

Download from http://www.nek.uu.se or from S-WoPEC http://swopec.hhs.se/uunewp/ 


\title{
Vacancy Referrals, Job Search, and the Duration of Unemployment: A Randomized Experiment*
}

\author{
by \\ Per Engström`, Patrik Hesselius` and Bertil Holmlund
}

February 1, 2009

\begin{abstract}
One goal of the public employment service is to facilitate matching between unemployed job seekers and job vacancies; another goal is to monitor job search so as to bring search efforts among the unemployed in line with search requirements. The referral of job seekers to vacancies is one instrument used for these purposes. We report results from a randomized Swedish experiment where the outcome of referrals is examined. To what extent do unemployed individuals actually apply for the jobs they are referred to? Does information to job seekers about increased monitoring affect the probability of applying and the probability of leaving unemployment? The experiment indicates that a relatively large fraction (one third) of the referrals do not result in job applications. Information about intensified monitoring causes an increase in the probability of job application, especially among young people. However, we find no significant impact on the duration of unemployment.
\end{abstract}

Keywords: vacancy referral, job matching, job search, randomized experiment. JEL-codes: C99, J64, J68.

\footnotetext{
${ }^{*}$ We thank Björn Blomqvist, Anders Forslund, Peter Fredriksson, Fredrik Jansson Dahlén, Tomas Jonsson, Bo Lundgren, Oskar Nordström Skans, Martin Nilsson, Petra Nilsson, Lena Olofsson, Kristina Padrón, Leif Tallskog, Roope Uusitalo and seminar participants at IFAU and the Public Employment Service for valuable comments. Special thanks to Kjell Hjelm, Rolf Adolfsson and Jan Eriksson at the Public Employment Service who skillfully managed all the practical details of the experiment. Patric Tirmén provided excellent research assistance. Financial support from The Swedish Unemployment Insurance Board (IAF) is gratefully acknowledged.

• IFAU and Department of Economics, Uppsala University. E-mail: per.engstrom@ifau.uu.se

• IFAU and Department of Economics, Uppsala University. E-mail: patrik.hesselius@ifau.uu.se

- Department of Economics, Uppsala University. E-mail: bertil.holmlund@nek.uu.se
} 


\section{Introduction}

The referral of unemployed job seekers to job vacancies is key instrument whereby the public employment service (PES) attempts to facilitate the matching between job seekers and vacancies. This instrument is also used as a device to monitor job search, thereby reducing the moral hazard problems in unemployment insurance. A job seeker who fails to apply for a job that he is referred to runs a risk of being sanctioned, i.e., being exposed to a benefit withdrawal or a benefit reduction. However, a credible threat of a benefit sanction requires that PES gathers and uses information on whether referrals lead to actual job applications.

Our study focuses on vacancy referrals in Sweden, a country well known for its ambitious active labor market policies. The vacancy referral process is a key ingredient of these policies. A vacancy referral involves a formal letter to the job seeker where a particular vacancy is identified. The letter states explicitly that the job seeker should apply for the vacancy and that failure to do so can result in a reduction or withdrawal of unemployment benefits. The annual flow of referrals via PES has amounted to some $13-18$ percent relative to the labor force (AMS, 2007a). A referral should take place when the PES administrator has found a job that is "suitable" to the job seeker. The suitability criterion is a bit vague but attempts to prevent "excessive" search for jobs where the qualification requirements would rule out successful matches. The two goals of the referrals matching and monitoring - may call for different priorities in the process: the more monitoring is emphasized, the less focus should be directed at referring the job seeker to suitable vacancies.

We examine how the vacancy referral process works and focus on three main questions. Do referrals lead to actual job applications? Does a "threat" of increased monitoring affect the probability of searching for a job that a worker is referred to? And how does this threat affect the duration of unemployment? To answer these questions, we have undertaken a randomized experiment based on a sample of vacancy referrals during the 
fall of 2007. Surveys to employers were used to get information about how often referrals lead to job applications. Some unemployed job seekers - the "treatment groups" - were alerted (via letters from PES) to an increased risk of being monitored, i.e., an increased probability that their referral would be checked with the employer.

We find that about one third of the referrals did not result in actual job applications. Information about increased monitoring resulted in a higher probability of job application. The average impact amounts to an increase in the job application rate by 4 percentage points. The impact is most pronounced - 12 percentage points - among young people. However, there is no statistically significant impact on the duration of unemployment.

We proceed by a brief overview of some related previous studies. Section 3 describes the experiment; section 4 discusses some theoretical issues; section 4 presents empirical results, and section 5 concludes.

\section{Previous studies}

We are unaware of previous studies that focus on vacancy referrals in the matching process. However, there are a number of related studies that deal with the effects of job search requirements and job search assistance (see Fredriksson and Holmlund, 2006, for a survey). Arguably, the most convincing evidence is based on work search experiments undertaken in the United States. One experiment was undertaken in the state of Washington in 1986-87 and is described in Johnson and Kleppinger (1994). Four different treatments were considered: (i) elimination of work-search requirement; (ii) standard requirement; (iii) individualized requirements; and (iv) intensive services. Individuals in the first category had essentially no search requirements. They were not required to report a specific number of employer contacts and UI payments were made automatically to claimants until they reported change of circumstance, such as return to work. The second category had requirements similar to what had been practiced in most states. Claimants had to make at least three employer contacts per week and those 
employers had to be listed on bi-weekly continued claims forms. Individuals in the third category were subject to work-search treatments tailored to specific circumstances of their occupation or local labor market. The fourth category had job search assistance early in the unemployment spell.

The study finds strong evidence that more stringent search requirements reduce the length of benefit receipt. Workers in the first category (no search requirements) had three weeks longer duration of benefit receipt than those with standard requirements. No search requirement also increased the risk of benefit exhaustion and increased the probability of being reemployed by the same employer. There is some evidence that workers in the first category had slightly higher reemployment wages in the short term, a finding consistent with higher reservation wages. However, there is no evidence of any longer-term effects on wages.

Another experimental study was undertaken in Maryland in 1994 and is presented in Benus and Johnson (1997). Benefit claimants were randomly assigned to four treatment groups and two control groups. The control groups were required to follow the standard requirements at the time, including the report of at least two employer contacts per week (although without any verification of the contacts). Participants in one of the control groups were informed that they were part of an experimental study. The treatments were as follows: (i) increased work-search requirements by requiring workers to make at least four employer contacts per week; (ii) requiring two employer contacts per week but without any requirement of documentation; (iii) a requirement that workers should attend a four-day job search workshop early during the unemployment spell; and (iv) information to the claimants that their reported employer contacts would be verified.

The results from the Maryland study suggest that increased search requirements can have non-trivial behavioral effects. Increasing the number of required employer contacts from two to four reduced the duration of benefit receipt by 6 percent. Informing claimants that their employer contacts would be verified reduced the duration of benefit receipt by 7.5 percent. Participation in the job search workshop reduced the number of benefit weeks by 
5 percent, a finding broadly consistent with results from other experiments undertaken in the United States. The effect could reflect enhanced skills in job search but may also reflect higher perceived costs of remaining on UI (as the workshop reduces time available for leisure). In fact, the Maryland study suggests that the latter interpretation may be most plausible. The effect is largely driven by a sharp increase in exit rates from unemployment prior to the scheduled workshop.

A study by Ashenfelter et al. (2005) also reports results from randomized experiments intended to measure whether stricter enforcement and verification of job search activities reduce UI claims. The experiments were implemented in four states - Connecticut, Massachusetts, Virginia and Tennessee - in 1984-85. The treatments included attempts to verify job search activities and also actual verifications (such as in depth interviews concerning the claimant's search effort and in some cases contacts with employers). The study finds at most a very small effect on benefit payments.

Dolton and O'Neill (1996) report evidence from the Restart experiments in the United Kingdom. Individuals with elapsed unemployment of six months were randomly assigned to participation in an interview to counsel them on active job search (the treatment group). Failure to attend the interview carried an explicit risk of losing benefits. The control group consisted of individuals that were not notified to attend an interview. The study reports that the notification of an interview had a statistically significant positive effect on exit rates to employment. The magnitude of the effect on the job exit rate is also substantial (around 30 percent).

Van den Berg and van der Klaauw (2006) report results from a small experiment undertaken at two local employment offices in the Netherlands. They discuss the tradeoff between formal and informal search, where formal search takes place via public employment offices and informal search involves other channels, such as gathering information from friends. The treatments entailed counseling as well as monitoring, both presumably affecting formal search. The study cannot find any support for the claim that monitoring and counseling raises the transition rate from unemployment to employment. 
The interpretation favored by the authors is that monitoring of formal search induced a substitution away from informal search channels.

Recent work by Hägglund (2006) presents some Swedish randomized experiments that shed light on search requirements and search assistance in active labor market policy. Hägglund (2006) describes one of those experiments, where a randomly selected treatment group of job seekers was exposed to intensified monitoring and job search assistance. The combined effects of the two treatments were to substantially increase the rate of outflow from unemployment. The control of search intensity had no independent effect.

Some recent Swedish non-experimental studies have in part dealt with the role of vacancy referrals; see IAF (2006) and Riksrevisionen (2005). Both these studies conclude that referrals are rarely followed up. In 2005, the Swedish PES introduced new rules so as to increase the follow-up of vacancy referrals. Among other things, these rules involved random checks with employers to verify job applications. However, these rules have not been comprehensively implemented. A study by PES (AMS, 2007a) reveals that 15 percent of referred seekers had not sent in a job application (according to the employers) despite the fact that they stated that they had done so.

\section{Design and implementation of the study}

The practical implementation of the experiment was done by the Public Employment Service. The referrals in the study were randomly selected during a 9-week period in August and September 2007. A number of criteria had to be fulfilled in order to be included in the treatment groups: (i) An employer could appear at most once among the referrals (so as minimize the employer's cost of participating). (ii) A job seeker could appear at most once in any of the treatment groups. (iii) Included referrals had a deadline 
for job application within (roughly) three weeks. ${ }^{1}$ (iv) Only referrals pertaining to individuals qualified for unemployment benefits (UB) were considered since a nonrecipient faces no risk of benefit sanction.

The sampling was made sequentially. Starting from the flow of all new referrals (about 10-15,000 each week) we apply conditions (iii) and (iv) above; this reduced the number of referrals to about 2-3,000. This group constitutes the population $(\mathrm{P})$ of referrals in the study. In the next step all employers and individuals that had been drawn prior weeks were removed from the population. In the final steps conditions (i) and (ii) were applied to the remaining population: first random exclusion of all but one of the referrals pertaining to the same employer, then random exclusion of all but one of the referrals pertaining to the same individual. The population thus consists of all referrals that had an a priori chance of selection.

With these criteria applied, some 500 referrals were included each week. Individuals were randomly allocated to three treatment groups denoted A, B and C. Group A was subject to increased monitoring via surveys to employers so as to verify job applications associated with referrals. In addition, the members of this group were informed by letter that a referral to a job opening would most likely be followed up through employer contacts. See Appendix A for a description of the information letter. People in group B were also subject to increased monitoring via surveys to employers but no "advance warning" was given to them. Group C received the same information letter as group A, but no employer contacts took place. Group D is defined as the remaining population of referrals after group $\mathrm{A}, \mathrm{B}$ and $\mathrm{C}$ have been removed, i.e. $\mathrm{D}=\mathrm{P}-(\mathrm{A}+\mathrm{B}+\mathrm{C})$.

The selection of referrals into the three groups was made each Friday between August 3 and September 28 ( 9 occasions in total). The letters to the job seekers were sent out as soon as the selection was made. The letters were expected to arrive approximately within a week after the individual had been given the referral.

\footnotetext{
${ }^{1}$ The formal criterion was that the "last day of publication" (at PES) should not exceed three weeks. In practice, this
} 
The survey to employers for group A and B was sent out shortly after the "last publication day" of the vacancy, which generally coincides with the last day for application. The timing was chosen so that the survey should arrive when the employer was actively handling the applications. The purpose was to reduce the effort of answering the survey and thereby increase the response rate. If the employer failed to answer the survey within a given time period, a reminder letter was sent out.

In addition to the question about whether a person referred to a vacancy actually applied for the job, questions were also asked about whether an applicant had the necessary qualifications ("realistic" application), if she was offered the job and if she accepted or turned down the job. ${ }^{2}$ The employer was also asked to report his subjective impression of whether or not the applicant appeared seriously interested in the job. See Appendix B.

Table 1 shows how different samples are used in our analyses. When exploiting the employer survey we compare group A (treatment) with group B (control), conditional on receipt of unemployment benefits (UB) at some point between the date of the referral and the vacancy's last day of publication. Receipt of UB includes individuals who receive compensation associated with participation in labor market programs. We observe from Table 1 that the response rates among groups A and B are virtually identical.

In the analysis of unemployment duration we also use sample $\mathrm{C}$; this group received the information letter but were not included in the employer survey. Unemployment duration is defined in terms of weeks of benefit receipt subsequent to the referral week. The treatment set consists of groups A and C and the control is group B. The analysis is conditioned on positive benefit receipt during the week when the referral was made.

\footnotetext{
criterion typically coincides with the deadline for job application.

${ }^{2}$ Responses regarding job offers and job acceptances are not used since we have found that some employers interpreted these questions differently than others.
} 
Table 2 shows some descriptive statistics. The differences in means are negligible and statistically insignificant across the three groups A, B and C. A comparison with group $\mathrm{D}$ reveals that there are fewer men in $\mathrm{D}$ as well as more prior referrals.

Table 1. Samples and response rates.

\begin{tabular}{llcccc}
\hline \hline Sample & Sample usage & A & B & C & D \\
\hline Overall sample & Descriptive statistics & 1504 & 1485 & 1506 & 22895 \\
Responses & Never used & 948 & 947 & & \\
$\begin{array}{l}\text { Response rate } \\
\begin{array}{l}\text { Response and some UB } \\
\text { between referral and last day } \\
\text { of publication }\end{array}\end{array}$ & Survey analysis & 782 & 799 & & \\
$\begin{array}{l}\text { Overall sample and some UB } \\
\text { during referral week }\end{array}$ & Duration analysis & 1148 & 1138 & 1118 & \\
\hline
\end{tabular}

Table 2. Descriptive statistics for samples (A, B and C) and population (D).

\begin{tabular}{lcccc}
\hline \hline Variable & $\mathrm{A}$ & $\mathrm{B}$ & $\mathrm{C}$ & $\mathrm{D}$ \\
\hline Male & 0.48 & 0.50 & 0.51 & 0.43 \\
Age (years) & 40.5 & 40.5 & 40.2 & 40.1 \\
Less than high school & 0.21 & 0.22 & 0.21 & 0.19 \\
High school & 0.48 & 0.47 & 0.49 & 0.48 \\
Some university education & 0.31 & 0.32 & 0.30 & 0.33 \\
Number of prior referrals 2006 and 2007 & 4.18 & 4.02 & 4.33 & 5.22 \\
Elapsed duration of UB receipt (days) & 129 & 128 & 130 & 136 \\
UB during referral period & 0.82 & 0.84 & 0.82 & 0.85 \\
\hline N & 1504 & 1485 & 1506 & 22895 \\
\hline Notes: The variables are dummies unless otherwise stated. "UB during referral period" is a dummy for some \\
UB receipt between the date of the referral and the last publication date of the vacancy.
\end{tabular}




\section{Theoretical issues}

We are interested in how intensified monitoring affects job applications and job findings. A positive impact on application rates is plausible, but it is not clear that this will translate into a positive impact on job findings. First, some applications are unlikely to meet the qualification requirements for the jobs; indeed, our survey indicates that only some 60 percent the applications were deemed "realistic" by the employers (see Table 3 below). Second, a higher propensity to adhere to formal search rules may come at the expense of informal search as discussed by van den Berg and van der Klaauw (2006). A worker who is induced to spend more time applying for referred vacancies may find less time to search via other channels, such as direct employer contacts. The link between job application and job finding is thus not immediate. In general, we expect that the impact on job finding should be weaker than the impact on application.

The impact of intensified monitoring on formal and informal search can be illustrated by means of a simple partial equilibrium model. ${ }^{3}$ Consider an unemployed worker who has access to two search channels, viz. formal and informal search. Informal search is not effectively monitored so there is no risk of a benefit sanction as a result of limited search effort. Formal search takes place via vacancy referrals undertaken by PES and the worker runs a risk of losing benefits if she fails to apply to a referred job. Let $s_{i}$ denote search effort along the formal $(i=1)$ and informal channel $(i=2)$, respectively. Job offers via the informal channel arrive at the Poisson rate $s_{2} \alpha$, where $\alpha$ is a measure of (exogenous) labor market conditions.

Vacancy referrals arrive at the Poisson rate $\mu$ and may result in a transition to work or a benefit sanction. Let $\mu s_{1} \lambda$ denote the probability per unit time of a job transition,

\footnotetext{
3 The model has similarities with the model in van den Berg and van der Klaauw (2006) but there are also differences. The job acceptance decision is trivial in our model since the wage offer distribution is degenerate by assumption. Our model focuses on vacancy referrals and the risk of a benefit sanction if search effort is deemed insufficient.
} 
where $\lambda$ is a measure of labor market conditions. ${ }^{4}$ The analogous probability of being exposed to a benefit sanction is $\mu \pi$, where $\pi=\pi\left(s_{1} ; \sigma\right)$ depends on search effort along the formal margin and the intensity of monitoring, $\sigma$. Holding monitoring constant, an increase in formal search should reduce the risk of being sanctioned. Holding formal search effort constant, an increase in monitoring should increase the sanction probability since more non-compliance is detected. We thus assume $\pi_{1}<0$ and $\pi_{2}>0$. We also assume $\pi_{12}<0$ which implies that a higher intensity of monitoring should increase the marginal return to search in terms of an increased probability of not being sanctioned.

Let $r$ denote the discount rate, $E$ the expected present value of employment, $U$ the value of unemployment and $S$ the value of a sanction. There is no wage dispersion so workers always accept job offers. Assuming an infinite time horizon, we can write the value function as:

$$
r U=b-c\left(s_{1}, s_{2}\right)+\mu s_{1} \lambda(E-U)+\mu \pi\left(s_{1} ; \sigma\right)(S-U)+s_{2} \alpha(E-U)
$$

where $b$ is unemployment benefits and $c\left(s_{1}, s_{2}\right)$ is the search cost function. For simplicity, we normalize the value of a sanction to zero. The search cost function is increasing and strictly convex in each argument. In addition, an arguably plausible property is $c_{12}>0$. Van den Berg and van der Klaauw (2006) make this assumption arguing that "the efforts along the two channels are relatively similar activities compared to most other ways to spend time and money."

The first-order conditions for an interior solution are:

$$
\begin{array}{ll}
s_{1}: & -c_{1}+\mu\left[\lambda(E-U)-\pi_{1} U\right]=0 \\
s_{2}: & -c_{2}+\alpha(E-U)=0
\end{array}
$$

\footnotetext{
${ }^{4}$ A natural benchmark is $\alpha=\lambda$, but this equality need not hold if informal and formal search cover different segments of the labor market. In any case, this is irrelevant for the results.
} 
The first terms in (2) and (3) capture the marginal costs of search. The second terms capture the marginal returns to search along the formal and informal channels. Note that the marginal return to formal search involves terms associated with the gain from job finding, $\lambda(E-U)$, as well as the reduced risk of benefit sanction, $-\pi_{1} U>0$. Assume for simplicity that employment is an absorbing state and treat $E$ as constant. The value of unemployment depends on the intensity of monitoring; a rise in $\sigma$ reduces the value of unemployment. ${ }^{5}$ It is thus clear that intensified monitoring affects the marginal return to formal search (via $\pi_{1}\left(s_{1} ; \sigma\right)$ and $\left.U(\sigma)\right)$ as well as the marginal return to informal search (via $U(\sigma)$ ). Assuming that the second-order conditions are satisfied, straightforward calculations based on (2) and (3) yield:

$$
\begin{aligned}
& \operatorname{sign} \frac{\partial s_{1}}{\partial \sigma}=\operatorname{sign}\left[-\mu \pi_{12} U c_{22}-\mu\left(\lambda+\pi_{1}\right) \frac{\partial U}{\partial \sigma} c_{22}+\alpha \frac{\partial U}{\partial \sigma} c_{12}\right] \\
& \operatorname{sign} \frac{\partial s_{2}}{\partial \sigma}=\operatorname{sign}\left[-\alpha \frac{\partial U}{\partial \sigma} c_{11}+\mu \pi_{12} U c_{12}+\mu\left(\lambda+\pi_{1}\right) \frac{\partial U}{\partial \sigma} c_{12}\right]
\end{aligned}
$$

where $c_{11}>0, c_{22}>0, \pi_{12}<0, \partial U / \partial \sigma<0$ and (probably) $c_{12}>0$. The signs of these expressions are ambiguous in general but the mechanisms are intuitive. The first term in the bracket of (4) is positive and captures that the marginal return to formal search increases via stronger incentives to avoid a sanction since $\pi_{12}<0$. The second term in the bracket of (4) incorporates the impact via the value of unemployment; the term cannot be signed since $\lambda+\pi_{1}$ can take either sign. The third term in (4) is negative and captures interactions between formal and informal search via the search cost function: an increase in informal search increases the marginal cost of formal search (and vice versa) if formal and informal search are "relatively similar activities" in the sense that $c_{12}>0$.

\footnotetext{
${ }^{5}$ Use (1) to obtain $U=\left[b-c(\bullet)+\mu s_{1} \lambda E+s_{2} \alpha E\right] /\left[r+\mu s_{1} \lambda+\mu \pi(\bullet)+s_{2} \alpha\right]$, where $\partial U / \partial \sigma<0$ since $\pi_{2}>0$.
} 
The impact of monitoring on informal search works via the value of unemployment and thereby the marginal return to search, $\alpha(E-U)$. The first term in (5) is positive since $\partial U / \partial \sigma<0$ and thus $\partial(E-U) / \partial \sigma>0$. Intensified monitoring would thus tend to increase informal search. However, this effect is counteracted by the second and possibly the third term. The second term is negative as long as $C_{12}>0$.

Summing up, it is not clear how intensified monitoring of vacancy referrals will affect formal and informal search. The overall impact on job finding, which depends on both types of search activities, is ambiguous. The properties of the search cost and monitoring technologies are crucial for the outcomes. Empirical evidence on these properties is, unfortunately, close to nonexistent.

\section{Empirical results}

\subsection{The survey}

Some basic results from the employer survey are reported in Table 3. Over 30 percent of referrals did not result in job applications. This number may perhaps appear to be on the high side but the lack of previous studies cautions against strong priors about what is reasonable or not. There is a presumption that the reliability should be higher for positions in the public sector since those employers are required to keep records on job applications. However, when we look separately on jobs that most likely pertain to the public sector, we find roughly the same rate of non-compliance. Moreover, a small survey to employers undertaken by PES during 2008 found that about 25 percent of the referrals did not result in job applications. 
Table 3. The survey results.

\begin{tabular}{|c|c|c|c|c|c|}
\hline Question & Group & Yes & No & $\begin{array}{c}\text { Unknown or } \\
\text { uncertain }\end{array}$ & $\mathrm{N}$ \\
\hline \multirow{3}{*}{$\begin{array}{l}\text { Applied for } \\
\text { the job }\end{array}$} & A & 0.68 & 0.32 & & 782 \\
\hline & B & 0.64 & 0.36 & & 799 \\
\hline & $t(\mathrm{~A}-\mathrm{B})$ & 1.65 & & & \\
\hline \multirow{3}{*}{$\begin{array}{l}\text { Interested in } \\
\text { the job }\end{array}$} & $\mathrm{A}$ & 0.65 & 0.10 & 0.25 & 530 \\
\hline & B & 0.64 & 0.08 & 0.28 & 510 \\
\hline & $t(\mathrm{~A}-\mathrm{B})$ & 0.46 & 1.00 & -1.14 & \\
\hline \multirow{3}{*}{$\begin{array}{l}\text { Realistic } \\
\text { application }\end{array}$} & A & 0.59 & 0.16 & 0.25 & 530 \\
\hline & $\mathrm{B}$ & 0.58 & 0.15 & 0.27 & 510 \\
\hline & $t(\mathrm{~A}-\mathrm{B})$ & 0.15 & 0.42 & -0.51 & \\
\hline
\end{tabular}

Notes: The $t$-statistics test for equality of the means.

\subsection{The impact of information on search behavior}

We now turn to a more detailed analysis of how the "threat" of a referral follow-up influences the probability of job application. We expect that those exposed to information about a probable follow-up would be more prone to obey the rules and apply for the job (although the theory is somewhat ambiguous about the direction of the effect).

By and large, this presumption is confirmed by the data; see Table 4. The application rate is 4 percentage points higher in treatment group A than in the B control. However, the difference is only marginally significant. The estimate and the standard errors are unaffected by the inclusion of control variables in the second column.

The three last columns of the table include results from alternative specifications. We consider interactions between treatment status and three indicators of labor market experience, namely the number of previous referrals, elapsed duration of unemployment, and age. The broad pattern that emerges is that labor market "inexperience" is associated with stronger responsiveness to the information treatment. 
In particular, those who are young or have short previous unemployment spells appear highly responsive; the estimates imply an impact on the application rate of 11 or 12 percentage points. We have also examined if the treatment effects vary by gender and education (not shown in Table 5). We find a significant effect for men (7 percentage points) but not for women. There is some evidence the effect is higher for individuals with relatively low education although the differences are only marginally significant. ${ }^{6}$

An intriguing question is why those with relatively little labor market experience appear to be the most responsive. We speculate that the results may reflect differential assessments of the information letter's implicit threat of benefit sanction. The "objective" risk of benefit sanction has been very low in Sweden: on average around 0.45 sanctions per month out of 100 benefit recipients took place in 2005, 2006 and 2007. ${ }^{7}$ Older individuals and those with experiences of long spells of unemployment have presumably learned that the risk of benefit sanction is very low, despite strict formal rules, and adjusted their behavior accordingly. For these groups, a reminder of the rules may not have much impact on the perceived sanction probability. However, those who have recently been introduced to the UI rules, including the rules that apply to vacancy referrals, may be more inclined to take seriously the wordings of the information letter. ${ }^{8}$

\subsection{The impact of information on unemployment duration}

As discussed above, it is not obvious that a positive impact of monitoring on job application will also imply a positive impact on job finding. Some applications are

\footnotetext{
${ }^{6}$ The impacts of the "other controls" (not shown) are as follows: The application probability is higher for women than for men, increases with age and education, but have no statistically significant relationship with the length of previous unemployment and the number of previous referrals.

${ }^{7}$ See AMS (2007b), p. 79. A sanction is implemented in two steps. First, a notification is sent from PES to the unemployment insurance fund. Second, a decision on sanction, given notification, is taken by an insurance fund. The estimate of 0.45 is obtained by multiplying the average notification rate $(0.54)$ by the average (conditional) sanction rate $(0.85)$.

8 "If you receive unemployment benefits you are required to apply for referred jobs according to the rules regarding unemployment insurance." See Appendix A.
} 
unlikely to meet the qualification requirements for the jobs. We have also noted that intensified monitoring of formal search may reduce workers' informal search.

We examine how the information treatment has affected subsequent UB receipt rather than job finding; the UB data are arguably of higher quality than the data on job finding. The data on UB receipt include benefit information on a daily basis. A transition out of unemployment is defined as non-receipt of UB during a whole week; the results are insensitive to alternative definitions, such as non-receipt during two weeks.

The treatment we are interested in is unlikely to have a permanent impact on job finding. The information letter specified explicitly the time frame of the referral experiment (August 15 to October 15, 2007). Referrals outside this period should thus not be subject to intensified follow-ups. However, it is conceivable that these dates are not well recalled at later dates. To the extent that individuals perceive a general increase in the likelihood of being exposed to a follow-up, the information letter may well have more long term effects on job finding. Ultimately, this is an empirical question. 
Table 4. Estimates of treatment effects. Dependent variable: Did the individual apply for the job? (Yes=1, No=0).

\begin{tabular}{lcc}
\hline \hline & $(1)$ & $(2)$ \\
\hline Intercept & 0.638 & \\
& $(0.017)$ & \\
& & \\
Treatment (A) & $0.039^{*}$ & $0.040^{*}$ \\
& $(0.024)$ & $(0.024)$
\end{tabular}

A and few previous

referrals

A and some previous

A and many previous referrals

A and short

A and intermediate

A and long

A and age $\leq 30$

A and age $>30$

\begin{tabular}{lccccc}
\hline Other controls & No & Yes & Yes & Yes & Yes \\
\hline R2 $(\%)$ & 0.17 & 1.53 & 1.86 & 2.18 & 1.73 \\
$\mathrm{~N}$ & 1581 & 1581 & 1581 & 1581 & 1581 \\
\hline
\end{tabular}

Notes: The estimation is by OLS. Standard errors are in the parentheses. Significance: ${ }^{*}=10 \% ; * *=5 \% ; * * *=1 \%$. Previous referrals (during 2006 and 2007): few $(0,1)$; some (2, 3, 4); many (5 or more). Unemployment history is measured as days of UB receipt. Short history ( $<100$ days); intermediate $(100-250)$; long $(>250$ days). The standard set of "other controls" include age, gender, level of education, number of previous referrals, and days of UB receipt. In the models with interactions we also include controls for the baseline effects of the variables that are interacted with the treatment dummy. 
We have studied the impact on unemployment duration through several approaches. First, we ran Cox regressions to explain exits from unemployment during a period that ends in week 14, 2008. At that date, only 16 percent of the spells were right-censored. Second, we ran a number of OLS regressions explaining the probability of remaining on UB after $x$ weeks after the referral, where $x$ is 4,8 and 12. That is, we focus on the labor market state relatively close to the referral period on the assumption that the information letter should have the strongest impact close to this period. For both of these approaches, we allowed for interaction terms along the lines of those in Table 4.

The results from the Cox regressions are shown in Table 5, whereas the results from the OLS regressions are shown in Appendix C. We do not find any significant treatment effects in any of these specifications. Thus, there is no evidence that advance warning about intensified follow-ups of referrals has any positive (or negative) impact on unemployment duration. The precise reasons for this result are unclear but we have emphasized that an impact on job application need not automatically imply an impact on job finding. The result may reflect a substitution of away from informal towards formal search. However, absent data on search this can be no more than a speculation. 
Table 5. cox regressions of unemployment duration.

\begin{tabular}{lccc}
\hline \hline & $(1)$ & $(2)$ & $(2)$ \\
\hline Treatment (A) & 0.011 & 0.007 & \\
& $(0.040)$ & $(0.040)$ & \\
$\begin{array}{l}\text { A and few previous } \\
\text { referrals }\end{array}$ & & 0.024 \\
$\begin{array}{ll}\text { A and some previous } \\
\text { referrals }\end{array}$ & & $(0.060)$ \\
$\begin{array}{l}\text { A and many previous } \\
\text { referrals }\end{array}$ & & 0.024 \\
& & & $(0.077)$ \\
& & -0.032 \\
& & $(0.073)$
\end{tabular}

A and short

unemployment history

A and medium

A and long

A and age $\leq 30$

A and age $>30$

\begin{tabular}{lccccc}
\hline Other controls & No & Yes & Yes & Yes & Yes \\
\hline $\mathrm{N}$ & 3404 & 3404 & 3404 & 3404 & 3404 \\
\hline
\end{tabular}

Notes: Unemployment duration is measured as weeks of UB receipt subsequent to the referral week. Standard errors are in the parentheses. See notes to Table 4 for details about the variables. The duration data are censored at week 14, 2008, where 16 percent of the spells are right-censored.

\section{Concluding remarks}

We have presented results from a randomized labor market experiment where job search among the unemployed are subject to intensified monitoring. The treatment involves information that PES will most likely contact the employer in order to verify job applications associated with vacancy referrals. We find that the threat of referral followups causes an increase in job application rates, especially among young people. However, we find no impact on unemployment duration. 
The possibility that intensified monitoring of formal search may have little impact on total search raises some doubts about the efficacy of such policies. However, there is so far rather limited evidence on the empirical relevance of this possibility. If similar experiments are undertaken in the future, it would be valuable to incorporate collection of more comprehensive data of job search activities.

Our study has focused on how the threat of benefit sanction affects search effort. Monitoring of job search can also affect workers' reservation wages and thereby their propensity to accept job offers. A complete analysis of monitoring and work-search requirements must consider the impact on job acceptance decisions along with the analysis of search effort. 


\section{References}

AMS (2007a), Återrapportering enligt regleringsbrevet för 2006 - Kontrollfunktionen i arbetslöshetsförsäkringen - Rapport 2, Dnr 05-3790-00, Arbetsmarknadsstyrelsen.

AMS (2007b), Arbetsmarknadsrapport 2007:2, Arbetsmarknadsstyrelsen.

Ashenfelter, O., Ashmore, D. and Deschenes, O. (2005), Do Unemployment Insurance Recipients Actively Seek Work? Randomized Trials in Four US States. Journal of Econometrics 125, 53-75.

Benus, J. and Johnson, T. (1997), Evaluation of the Maryland Unemployment Insurance Work Search Demonstration. Report prepared for Maryland Department of Labor, Battelle Memorial Institute in conjunction with Abt Associates Inc.

http://wdr.doleta.gov/owsdrr/98-2/

Dolton, P. and O'Neill, D. (1996), Unemployment and the Restart Effect: Some Experimental Evidence, Economic Journal 106, 387-400.

Fredriksson, P. and Holmlund, B. (2006), Improving Incentives in Unemployment Insurance: A Review of Recent Research, Journal of Economic Surveys 20, 375-386,.

Hägglund, P. (2006), Are there pre-programme effects of Swedish active labour market policies? Evidence from three randomised experiments, IFAU Working Paper 2006:2.

IAF (2004), Arbetsmarknadsverkets handläggning av ärenden som rör arbetslöshetsförsäkring m m, IAF-rapport 2004:5. http://www.iaf.se

IAF (2005), Redovisning av tillämpningen av regelverket för lämpligt arbete, IAFrapport 2005:16. http://www.iaf.se

IAF (2006), Anvisning till ledig plats, IAF-rapport 2006:5. http://www.iaf.se

Johnson, T. and Klepinger, D. (1994), Experimental Evidence on Unemployment Insurance Work-Search Policies. Journal of Human Resources 29, 695-717.

Riksrevisionen (2005), Arbetslöshetsförsäkringen - kontroll och effektivitet, RiR 2005:3. http://riksrevisionen.se

Van den Berg, G. and van der Klaauw, B. (2006), Counseling and Monitoring of Unemployed Workers: Theory and Evidence from a Controlled Social Experiment. International Economic Review 47, 895-936. 


\section{Appendix A. The letter to groups A and C}

\section{Monitoring of job referrals}

You have been selected for a specific follow up of job referrals. The follow up pertains to referrals between August 15 and October 15 2007. If you are referred to a vacancy during this period, the Public Employment Service will with high probability contact the employer regarding your application.

The fact that you have been selected has nothing to do with earlier referrals that you might have received. The selection was random and covered the whole country.

The purpose is to study the Public Employment Service's referrals to vacancies. The result of the study will be processed and handled confidentially.

If you receive unemployment benefits you are required to apply for referred jobs according to the rules regarding unemployment insurance.

Questions may be sent to anvisningsstudie@ams.amv.se

Or call the Public Employment Service's customer service, 010 - 4872476.

If you want to know more about the Public Employment Service, please visit www.arbetsformedlingen.se

The Public Employment Service 


\section{Appendix B. The survey to employers}

1. Did the job seeker apply for the referred job?

Yes

No $>>>>$ exit survey

2. Did you get the impression that the applicant was seriously interested in the job?

Yes

No

Uncertain

Do not know, lack of information

Comment:

3. Was the referral realistic in the sense that the applicant met the formal/informal qualifications?

Yes

No

Uncertain

Do not know, lack of information

Comment:

4. Did the applicant get the job?

Yes

No

Vacancy not yet filled

Comment:....

5. If the answer on the fourth question was "No": Why didn't the applicant get the job?

$\mathrm{He} /$ she turned down the job

It was offered to another applicant

Comment: 


\section{Appendix C. Further results on unemployment duration}

Table C1. OLS regression explaining the probability of UB receipt 4 weeks after referral

\begin{tabular}{|c|c|c|c|c|c|}
\hline & $(1)$ & (2) & (3) & (4) & (5) \\
\hline Intercept & $\begin{array}{c}0.772 \\
(0.012)\end{array}$ & & & & \\
\hline Treatment (A) & $\begin{array}{c}0.000 \\
(0.015)\end{array}$ & $\begin{array}{c}0.000 \\
(0.015)\end{array}$ & & & \\
\hline
\end{tabular}

$\begin{array}{lc}\text { A and few previous } & 0.028 \\ \text { referrals } & (0.023) \\ \text { A and some previous } & -0.040 \\ \text { referrals } & (0.029) \\ \text { A and many previous } & -0.005 \\ \text { referrals } & (0.028)\end{array}$

A and short

0.020

unemployment history

$(0.021)$

A and medium

$-0.020$

unemployment history

$(0.030)$

A and long

$-0.014$

unemployment history

$(0.029)$

\begin{tabular}{lccccc} 
A and age $\leq 30$ & & & & & 0.000 \\
& & & & & $(0.031)$ \\
A and age $>30$ & & & & & 0.000 \\
& & & & & $0.017)$ \\
\hline Other controls & No & Yes & Yes & Yes & Yes \\
\hline $\mathrm{N}$ & 3404 & 3404 & 3404 & 3404 & 3404 \\
\hline Notes: Standard errors in parentheser. See also & & & & &
\end{tabular}


Table C2. OLS regression explaining the probability of UB receipt 8 weeks after referral

\begin{tabular}{lccccc}
\hline \hline & $(1)$ & $(2)$ & $(3)$ & $(4)$ & $(5)$ \\
\hline Intercept & 0.686 & & & & \\
& $(0.014)$ & & & & \\
Treatment (A) & -0.011 & -0.010 & &
\end{tabular}

A and few previous

$-0.004$

referrals

$(0.025)$

A and some previous

$-0.035$

referrals

$(0.033)$

A and many previous

0.002

referrals

$(0.031)$

$\begin{array}{lc}\text { A and short } & -0.001 \\ \text { unemployment history } & (0.024) \\ \text { A and intermediate } & -0.016 \\ \text { unemployment history } & (0.034) \\ \text { A and long } & -0.024 \\ \text { unemployment history } & (0.033)\end{array}$

\begin{tabular}{lccccc} 
A and age $\leq 30$ & & & & -0.032 \\
& & & & $(0.035)$ \\
A and age $>30$ & & & & & -0.004 \\
& & & & & $(0.019)$ \\
\hline Other controls & No & Yes & Yes & Yes & Yes \\
\hline $\mathrm{N}$ & 3404 & 3404 & 3404 & 3404 & 3404 \\
\hline Notes: Standard errors in & & & &
\end{tabular}


Table C3. OLS regression explaining the probability of UB receipt 12 weeks after referral.

\begin{tabular}{lccccc}
\hline \hline & $(1)$ & $(2)$ & $(3)$ & $(4)$ & $(5)$ \\
\hline Intercept & 0.590 & & & & \\
& $(0.015)$ & & & & \\
Treatment (A) & 0.003 & 0.003 & & &
\end{tabular}

A and few previous

0.006

referrals

$(0.027)$

0.008

$(0.034)$

$-0.007$

$(0.033)$

referrals

A and many previous

referrals
0.010

$(0.025)$

$-0.009$

$(0.035)$

$-0.005$

(0.034)

A and long unemployment history

A and age $\leq 30$

A and age $>30$

Other controls

No

Yes $(0.020)$

$\mathrm{N}$ 3404 3404 Yes Yes Yes

Notes: Standard errors in parentheses. See also Table 4. 
WORKING PAPERS*

Editor: Nils Gottfries

2007:21 Karin Edmark, Strategic Competition in Swedish Local Spending on Childcare, Schooling and Care for the Elderly. 38pp.

2007:22 Fredrik Johansson, How to Adjust for Nonignorable Nonresponse: Calibration, Heckit or FIML? 25pp.

2007:23 Henry Ohlsson, The legacy of the Swedish gift and inheritance tax, 18842004. 25pp.

2007:24 Ranjula Bali Swain and Fan Yang Wallentin, DOES MICROFINANCE EMPOWER WOMEN? Evidence from Self Help Groups in India. 26pp.

2007:25 Bertil Holmlund and Martin Söderström, Estimating Income Responses to Tax Changes: A Dynamic Panel Data Approach. 34pp.

2007:26 N. Anders Klevmarken, Simulating the future of the Swedish baby-boom generations. 60pp.

2007:27 Olof Åslund and Oskar Nordström Skans, How to Measure Segregation Conditional on the Distribution of Covariates. 17pp.

2007:28 Che-Yuan Liang, Is There an Incumbency Advantage or a Cost of Ruling in Proportional Election Systems? 20pp.

2007:29 Stefan Eriksson and Jonas Lagerström, Detecting discrimination in the hiring process: Evidence from an Internet-based search channel. 31pp.

2007:30 Helge Berger and Pär Österholm, Does Money Growth Granger-Cause Inflation in the Euro Area? Evidence from Out-of-Sample Forecasts Using Bayesian VARs. 32pp.

2007:31 Ranjula Bali Swain and Maria Floro, Effect of Microfinance on Vulnerability, Poverty and Risk in Low Income Households. 35pp.

2008:1 Mikael Carlsson, Johan Lyhagen and Pär Österholm, Testing for Purchasing Power Parity in Cointegrated Panels. 20pp.

2008:2 Che-Yuan Liang, Collective Lobbying in Politics: Theory and Empirical Evidence from Sweden. 37pp.

2008:3 Spencer Dale, Athanasios Orphanides and Pär Österholm, Imperfect Central Bank Communication: Information versus Distraction. 33pp.

2008:4 Matz Dahlberg and Eva Mörk, Is there an election cycle in public employment? Separating time effects from election year effects. 29pp.

\footnotetext{
* A list of papers in this series from earlier years will be sent on request by the department.
} 
2008:5 Ranjula Bali Swain and Adel Varghese, Does Self Help Group Participation Lead to Asset Creation. 25pp.

2008:6 Niklas Bengtsson, Do Protestant Aid Organizations Aid Protestants Only? $28 \mathrm{pp}$.

2008:7 Mikael Elinder, Henrik Jordahl and Panu Poutvaara, Selfish and Prospective Theory and Evidence of Pocketbook Voting. 31pp.

2008:8 Erik Glans, The effect of changes in the replacement rate on partial retirement in Sweden. 30pp.

2008:9 Erik Glans, Retirement patterns during the Swedish pension reform. 44pp.

2008:10 Stefan Eriksson and Jonas Lageström, The Labor Market Consequences of Gender Differences in Job Search. 16pp.

2008:11 Ranjula Bali Swain and Fan Yang Wallentin, Economic or Non-Economic Factors - What Empowers Women?. 34pp.

2008:12 Matz Dahlberg, Heléne Lundqvist and Eva Mörk, Intergovernmental Grants and Bureaucratic Power. 34pp.

2008:13 Matz Dahlberg, Kajsa Johansson and Eva Mörk, On mandatory activation of welfare receivers. 39pp.

2008:14 Magnus Gustavsson, A Longitudinal Analysis of Within-Education-Group Earnings Inequality. 26pp.

2008:15 Henrique S. Basso, Delegation, Time Inconsistency and Sustainable Equilibrium. 24pp.

2008:16 Sören Blomquist and Håkan Selin, Hourly Wage Rate and Taxable Labor Income Responsiveness to Changes in Marginal Tax Rates. 31 pp.

2008:17 Jie Chen and Aiyong Zhu, The relationship between housing investment and economic growth in China : A panel analysis using quarterly provincial data. 26pp.

2009:1 Per Engström, Patrik Hesselius and Bertil Holmlund, Vacancy Referrals, Job Search, and the Duration of Unemployment: A Randomized Experiment. $25 \mathrm{pp}$.

See also working papers published by the Office of Labour Market Policy Evaluation http://www.ifau.se/

ISSN 1653-6975 